\title{
AN INTEGRATED BIM-GIS PLATFORM FOR REPRESENTING AND VISUALIZING 3D CADASTRAL DATA
}

\author{
D.E. Andrianesi* and E. Dimopoulou \\ School of Rural and Surveying Engineering, National Technical University of Athens, 9 Iroon Polytechneiou str, 15780 Zografou, \\ Greece (andrian.surv@gmail.com; efi@survey.ntua.gr)
}

\author{
Commission VI, WG VI/4
}

KEY WORDS: Building Information Model (BIM), Geographic Information Systems (GIS), Industry Foundation Classes (IFC), 3D Ownership Rights, Open Standards, Interoperability, Web Technology

\begin{abstract}
:
The rapid urbanization over the last decades is leading to intensive land exploitation, and thus to the degradation of the city environment and the surrounding areas. This reality that applies at a global level, challenges new needs for sustainable growth and new ways to protect and ensure land property. It is of great importance, for the viable growth of every organized social structure, to protect land ownership and land-use in an appropriate way. Therefore arises the need for continuous and valid update of the complex Rights, Restrictions and Responsibilities (RRRs) within a developing 3D urban environment. For this environment, the interest focuses on ensuring land properties by improved methods of 3D information management, within modern land administration systems. The integration of Building Information Models (BIMs) and Geographic Information Systems (GIS) is expected to produce various advantages and play an important role in constructing 3D city models that successfully deal with every challenge in the urban landscape. GIS, in one hand, can manage and provide information about the existing environment, while on the other hand, BIMs focus on information regarding the design, construction and maintenance of a building /or complex structure inside that environment. This paper discusses the development of an integrated GIS and BIM 3D data platform enriched with 3D cadastral information This is illustrated with two use cases, a city block (No 464) in the area of Chalandri, Athens, and a four-floor building (at Kithaironos 21 street, in the same buildings' block), used for applying BIM technology.
\end{abstract}

\section{INTRODUCTION}

Over the last two decades, rapid urbanization has resulted in substantial pressure on development and use of land in urban environments. This trend has led to structures and space usages of complex buildings above and underground, creating complex and vertically stratified ownership RRRs. The current twodimensional (2D) land administration systems cannot fully manage these complex arrangements since the $3 \mathrm{D}$ property formation is registered based on 2D documentation and the legal property boundaries are shown on $2 \mathrm{D}$ cadastral maps and drawings.

In the Greek jurisdiction the extent of real property is defined above the surface and below the ground, while the Cadastre collects information on property objects in reference to the twodimensional land-parcel. The Special Real Property Objects (SRPO) (such as 'Ypospaka','Anogeia') and the Mines are the only 3D entities included in the existing cadastral model in Greece, although not spatially represented (Dimopoulou et al., 2012). This approach has limitations to represent the actual extent of complicated 3D property units and also to provide an overview of a 3D Land Administration System (LAS). An important source of this information can be 3D web-based city models, which provide geometrical and functional properties about land formation and use at a city scale.

Linking cadastral information to 3D digital representation of the urban environment could be a promising approach in order to define and visualize 3D legal spaces. BIM and GIS are considered as $3 \mathrm{D}$ digital models that have capabilities to identify property units, represent cadastral boundaries and visualize complex buildings in detail and accurately. BIM focuses on micro-level representation of buildings, while GIS on macro-level representation of their external environments (Wang et al., 2019). While a LAS includes urban planning and management, BIMs are not suitable for visualizing data on city level. However, by using an integrated approach of GIS and BIM, it is possible to visualize $3 \mathrm{D}$ cadastral information on a city scale with additional semantic data accordingly, when required.

Considering the related work carried out in the last decade, the aim of this paper is to combine data from GIS and BIM, investigating new methods for managing 3D cadastral information and building data in high detail scale within a common platform. In particular, Revit as BIM software and ArcGIS Pro as GIS were used and the adequacy of IFC open BIM data standard for the exchange and linkage of the 3D spatial information with the two systems was tested. IFC standard can be considered as a viable data model for 3D management and visualization of complex RRRs that comprises a set of spatial and semantic data and ArcGIS Pro, as shown by previous research, was selected in conjunction with the last release of this system that provides a range of tools for bringing geographic context to BIM data.

This study exploits data of the city block 464 in the area of Chalandri, Athens, while the building used for applying BIM technology is a newly four-floor building at Kithaironos 21 street, in the same buildings' block.

The results indicate that the developed platform gives helpful basic functions and enables a proper information exchange among different units due the interoperable character of the IFC. 
Nevertheless, some limitations were appeared in IFC format during the process of connecting the two systems, leading to semantic data loss.

The paper is structured as follows. Section 2 provides a theoretical background of BIM and GIS systems. Section 3 investigates the adequacy of BIM and GIS data as input in a 3D LAS (Kalogianni et al., 2020). To this purpose, LASs, models of physical and legal space are described as well as the IFC as a widely used open data model for exchanging and representing $3 \mathrm{D}$ spatial information. At the end of this section, related work is also analyzed. This is followed by the implementation of the platform and the results provided in Section 4. In the final section, the paper concludes with conclusion and further research directions.

\section{THEORETICAL BACKGROUND}

\subsection{Building Information Model-Modelling-Management (BIM)}

BIM was introduced as the most comprehensive and intelligent 3D digital approach for managing complex buildings, enabling stakeholders with diverse backgrounds to communicate in a common data environment (Atazadeh et al., 2019). This acronym refers to three distinct contexts: product (model), process (modelling) and information (management). As a process, BIM is an approach to create, manage, derive and share building information among the involved stakeholders. The result of BIM process is a BIM product which includes 3D digital spatial information as well as semantic information about a construction (Atazadeh et al., 2016). At last, BIM as management emphasizes on the information itself and use and reuse of digital construction information throughout the entire lifecycle of the project (Oldfield et al., 2017). In this research, the BIM acronym receives all the meanings, depending on the phase of lifecycle.

BIM belongs to object - based parametric modelling tools. This means that the objects are defined as parameters and relations to other objects in a project, so that if there are changes in a related object, dependent or adjacent ones will automatically change or adjust, as well (Eastman, 2009). Each model element is semantically rich providing information on a cost estimate as well as material tracking and ordering. Adding specific parameters to the existing information contained in BIM enhance the data associated with a model to share a greater level of understanding of a construction project.

Depending on the type of parameters, BIM is evolving from third (3D) to seventh (7D) dimension. Each dimension has its own purpose and is related to the duration, timeline and scheduling of a project (4D), as well as cost (5D) and future sustainability (6D), reaching the seventh dimension when everything linked to facility management process is collated in a single place within the BIM to be used at a future stage (Arunkumar et al., 2018).

As a project passes through different phases, the level of development (LOD) in a BIM model also increases to different levels namely LOD 100 to LOD 500. Each LOD signifies the degree to which the stakeholders of a project can rely on information associated with an object. Namely, LOD 100, LOD 200 and LOD 300 refer to concept, schematic and detailed design accordingly, while LOD 350, LOD 400 and LOD 5 have to do with construction documentation, fabrication and assembly approaching the final level, the as-built construction. In parallel, LOD is usually interpreted as a Level of Detail instead of Level of Development. Level of Detail is actually what proportion detail is enclosed within the model element and can be thought of as input to the element, while the Level of Development is a reliable output (United BIM, 2018).

Ultimately, BIM data could be classified into two file formats, proprietary data (e.g. .rvt \& dxf) and nonproprietary data like IFC. IFC (as detailed in the section 3.3), has been developed by the buildingSMART alliance as an open international standard for BIM (American Institute of Architects, Keith E. Hedges, 2017). It is widely used in AECO industry as it can exchange and share information among software applications by many different stakeholders and define building data elements, showing the spatial relationship among them by IFC schema (Borrmann, 2018).

\subsection{Geographic Information System (GIS)}

Geographic Information System (GIS) is a system designed to capture, store, manipulate, analyze, manage, and present spatial or geographic data. (Clarke, 1986). GIS is referred as an effective problem-solving tool, through spatial analysis due to the coexistence of two data types, spatial and attribute data. This system provides an infrastructure for creating maps, releasing geographic information available throughout an organization, across a community, and openly on the Web. Using these maps, users can identify problems, monitor changes, perform forecasting, improve decision-making leading to cost savings, find different kind of trends within the community and manage and respond to events (Maliene et al.,2018).

A working GIS integrates hardware, software, data and people as key components. In particular, people manage the system and develop plans for applying, while data is referred as the most important component of a GIS (Kanickaraj, 2018). Hardware is the computer on which a GIS operates, and GIS software involves a broad range of applications which encompass the use of a combination of digital maps and georeferenced data.

GIS software can be sorted into open source and notable commercial or proprietary. Grass GIS, Jump GIS, QGIS and Saga GIS belong to the first category as long as products of Esri (ArcGIS), Bentley Systems, Autodesk and ENVI are recorded to the second one. To conclude, many suppliers are starting to offer Internet based services namely Saas (Software as a Service) like ArcGIS Online-CartoDB-Mapbox, Paas (Platform as a Service) like ArcGIS Online-Google Maps JavaScript API and Daas (Data as a Service) like ArcGIS Online-Google Maps-OpenStreetMap.

\section{CAN DATA FROM BIM \& GIS BE USED AS INPUT FOR A 3D LAS?}

The current societal demand for a lifecycle-thinking is driving the need to integrate independent systems with methodologies, associated with different aspects of the Spatial Development lifecycle (SDC) (Kalogianni et al., 2020). Land Administration Systems (LASs) are an important component of the SDC, as this term is used to refer to the processes of recording and disseminating information about the relationship between land and people.

The majority of the current adopted LASs in developed and developing countries are based on 2D registration. However, facing the rapid urbanization and digital transformation, those systems need re-engineering to extend into 3D (Oosterom et al., 2018). In this paper the term ' $3 \mathrm{D}$ LAS' replaces the term ' $3 \mathrm{D}$ Cadastre' since the first cover both legal and spatial aspects, indicated as Land Registry and Cadastre (Kalogianni et al., 2020). 
As stated by Enemark (2009), cadastral systems operate as a multipurpose engine that serve administration functions in land tenure, value, use and development and are focused on delivering sustainable land management. Therefore, those systems could even be considered as LASs.

The two main dimensions of a LAS for 3D management of land and property are legal and physical elements (Aien et al., 2013). At one hand, legal information is a prerequisite for managing RRRs and is associated with concept of legal spaces. The term legal entities includes the invisible cadastral objects that are defined by the second dimension, physical objects. The latter refers to geometric and semantic components. Geometric information is related to shape and geometric aspects of buildings' elements while semantic data includes the attributes of them.

The need from the real world to align to technological developments is characterized as the one of the key drivers to move toward 3D registrations in LASs. Recent advancements in methods and techniques are becoming mainstream in developing 3D physical models. Detailed BIMs, IFC open data models for BIMs, 3D GIS techniques, CityGML and InfraGML data models, 3D CAD, 3D web visualisation platforms and 'Smart Cities' applications are examples of those new methods. Regarding legal data models, mainly Land Administration Domain Model (LADM) and others, such as e-plan, have been widely used for managing and maintaining property interests. Principally, physical objects can be connected to legal data models through external linkages. However, the need for integrating those two basic dimensions has been investigated in recent years and various approaches are being developed.

In the next sub-sections BIM/IFC and City models are described as means to represent the physical components and IFC as integrated approach of legal and physical information. To conclude this section, related recent research is highlighted.

\subsection{Physical models}

BIM, IFC and 3D GIS have capabilities to represent geometric entities with the associated semantic data. Thus, cadastral boundaries and complex buildings can be visualized, identifying property units. BIM/IFC focuses on the building element properties of a single building down to the construction components, while city models via GIS methods focus on buildings in a larger scale up to entire cities (Sun at al., 2019). While a 3D LAS may be also used in urban planning and management, BIMs are inadequate for visualizing, analyzing and managing 3D RRRs on a city level. Therefore, it is a challenge to visualize the $3 \mathrm{D}$ extent of a LAS on a city level via city models in conjunction with BIMs, where diverse information is included depending on requirements.

\subsubsection{BIM/IFC}

As described in section 2.1, BIM is a digital representation of buildings and building components in the lifecycle phases. A BIM model encompasses geometry data and building information, supporting the management of land and property information in complex buildings. In addition, BIM environment offers a wide variety of physical elements, such as walls, doors, windows and floors.
IFC standard was developed by BuildingSMART in order to allow different BIM tools to communicate with each other and share data using a common format. Besides, IFC is an open BIM data model which includes physical entities that describe the whole lifecycle of buildings and link 3D cadastral data to the physical world. Physical entities in IFC are defined as subclasses of the 'IfcProduct' entity, in a hierarchical data structure. Specifically, physical information is defined by two main entities, namely 'IfcSpatialStructureElement' for spatial elements (IfcSite, IfcBuilding, IfcBuildingStorey, IfcSpace) and 'IfcBuildingElement' for physical building elements. The latter constitute the primary parts of the building, including elements likewise BIMs, for instance walls (IfcWall), windows (IfcWindow) and floors (IfcFloor). The placement of those elements can be absolute, constraint and relative. The absolute placement is relative to the world coordinate systems while constraint to the grid axes. Finally, relative places the entities in proportion to the other components.

Nowadays, BIM/IFC has been used as geometry model and integrated with 3D Cadastre (Sun et al., 2019), as described in the next sub-section (3.2).

\subsubsection{D City models}

A 3D city model is a digital model of urban areas with all its features in the three-dimensional scale, namely terrain surfaces, sites, buildings, vegetation, utility network and infrastructure. Components of 3D city models such as 2D GIS data, 3D objects and $3 \mathrm{D}$ scenes are encoded by specific formats like GeoTIFF / AutoCAD DXF, 3DS and Collada accordingly and have to be transformed into a common geographic coordinate system.

The most commonly used specification in $3 \mathrm{D}$ city models is the XML-based open standardized geometry model CityGML that represents geometric and semantic properties for applications such as urban planning and facility management. There are five defined levels of detail (LOD) from LOD0 that represents 2D footprints of buildings to LOD4 that includes interior and exterior architectural models. The base information to build a 3D city model is provided by GIS data. The latter includes a diverse set of elements from road networks to cadastral data that can be converted to $3 \mathrm{D}$ models for example in the case of extruded building footprints.

In addition, 3D city models can be used for a multitude of purposes in a growing number of different application domains, namely navigation systems, urban planning and architecture, GIS, emergency management, spatial analysis, land management and Spatial data infrastructures (Biljecki et al., 2015). Addressing the new challenges in terms of urban sustainability that threat the three pillars of sustainability (economic, social and environmental) as a holistic view relevant to land property, a 3D city model seems to be a positive approach.

To conclude, in the view of city governance in terms of the land property, 3D city models with integrated information are needed. City governments are believed to ensure the equitable use of land without diminishing the future generations' need (Zhixuan et al., 2015). Therefore, as described in the following sub-section 3.3, city models with efficient 3D information from BIM and GIS systems are capable to provide city planning tools, facilitating industry boom and productive 3D city governance, considering 3D land and property ownership interests. 


\subsection{Legal models -IFC Approach}

Most of the legal data models have been developed based on 2D land-parcels, being inefficient for the representation of the spatial dimension of 3D RRRs (Atazadeh et al., 2017). Currently, few cadastral data models like LADM and e-Plan may support 3D parcels to manage 3D RRRs but so far with limited capabilities. Furthermore, most of them do not include sufficient semantic information about 3D properties. Last but not least, legal entities do not internally incorporate physical information, except for connecting them via external links.

In the BIM domain, IFC standard alleviates issues related to exchange of BIM data and enables multiple BIM platforms to interact in an interoperable way (ISO16739 2013). Since the IFC standard comprises a set of spatial and semantic data, it is suggested that it could be considered as a viable data model for 3D management and visualization of complex RRRs. As described in 3.1.1 section, IFC entities for 3D RRR data management are classified into two main categories, namely physical and spatial elements. There are two entities for mapping ownership arrangements in the second category: IfcSpace and IfcZone (Atazadeh et al., 2019). IfcSpace in an entity that represents volumetric spaces inside a building. Thus, each legal space can be included into this entity while a set of spaces constitute the IfcZone entity. It is worth mentioning that IfcRelSpaceBoundary entity that is included in the IFC standard gives researchers the potential to define physical and virtual boundaries with or without physical elements referenced accordingly.

Furthermore, additional cadastral and legal attributes can be assigned to spatial entities via IfcPropertySet entity using the objectified relationship IfcRelDefinesByProperties. In this respect, legal documents (such as titles, property description and mortgages) can be referenced externally in the IFC standard via 'IfcExternalInformation' entity and its subclass 'IfcDocumentInformation'. Lastly, actors who have a particular interest (RRR) in 3D legal properties being a person, an organization or a group are defined with the 'IfcActor' entity. This entity is developed to represent the stakeholders and human agents involved in the development cycle of an IFC project (BuildingSMART 2013b). Every attribute is assigned to related entity via the aforementioned IfcPropertySet entity.

To conclude, encoding 3D legal property objects into IFC standard would provide sufficient semantic information about RRRs, which can empower the interoperable character of LASs with other urban systems. This integration of legal and physical information would prevent data integration issues and inconsistencies (Atazadeh et al., 2016). Therefore, this enrichment of the IFC standard would boost the functionality of BIMs in terms of controlling the lifecycle of buildings.

\subsection{Related work}

The topic of this section is the related work executed over the last decade, concerning the integration of cadastral information within BIM and GIS systems. Cadastral systems can be linked with broader environmental data aiming at supporting urban management (Rajabifard, 2014).

Sun et al. (2019), explored the possibility to utilize BIM and GIS for representation and visualization of $3 \mathrm{D}$ land property information. The framework was based on LADM model for legal entities and IFC/CityGML standard for the physical entities on building and city level accordingly. The result of this attempt was promising on both conceptual level and data level, facilitating the coexistence of cadastral units, AECO components and surveying units on a broader level (e.g. municipality level, city level).

Meulmeester in his thesis (2019), enriched IFC BIMs with legal space and used as 3D representation, showing a potential method on how to use the IFC data format to register legal space for land administration purposes, in particular apartment rights in the Netherlands. Moreover, the extensibility of the cadastral user defined property set by applying it to other elements than IfcSpaces, such as IfcWall and IfcFloor was presented, thus offering a context for defining legal space in other legal systems.

El-Hallap et al. (2019), highlighted the great need to adopt a smart 3D city model in order to enhance sustainable urban development using BIM and GIS systems. Sheikh Hamad city, northeast of the city of Asdaa Media, was selected as case study because of the intense urbanization. ArcGIS Pro was chosen as GIS Software, Google Sketchup as BIM one and Collada file format for the transformation of data between those systems. The expected benefits of this approach were to build and manage a 3D geometric and descriptive database for the various data used from stakeholders, as well as to provide citizens with the required information so as to contribute to improved management of infrastructure and facilities. LASs are an integral part of that 3D city model since they protect and ensure land properties, improving the quality of citizens' life.

Janecka (2019), presented an overall of the ongoing standardization activities with focus on 3D Cadastre and BIM and illustrated their connection with smart cities. This attempt derived from the fact that 3D land and property ownership information can serve for effective planning of healthy and productive smart cities. 3D BIM models are an important and detail source of data for 3D spatial units (Rajabifard, 2014; Oosterom et al., 2014; Oldfield et al., 2016; Atazadeh et al., 2017; Dimopoulou et al., 2018). The transforming mechanisms, referred in detail at his research, are needed in order to enable wider usage of BIM data in GIS projects dealing with smart cities.

Last but not least, LandInfra (Land and Infrastructure) standard, developed by the OGC (Open Geospatial Consortium) with GML encoding InfraGML, is a relatively new open standard that overlaps with other open standards in BIM (IFC) and 3D GIS (CityGML). Kumar et al. (2019), analyzes this standard that focuses on modeling and representing land and infrastructure features, trying to bridge the gap between BIM and GIS. 3D digital management of property interests in the building complexes is one of the use cases benefiting from BIM-GIS integration through LandInfra. The latter provides a step further in managing 3D spatial units concerning IFC and CityGML, as cadastral information and ownership rights can be associated with subsurface infrastructure and networks. 


\section{METHODOLOGY AND CASE STUDY}

\subsection{Methodological steps}

In this section the methodology for the integration of BIM and GIS via an online platform is described, in order to visualize and represent 3D land administration data at building and block scale.

For the current research Revit was used as BIM Software, IFC as the open BIM data standard for exchanging 3D spatial information and ArcGIS Pro as GIS system in an integrated manner. The first step was the creation of a 3D physical model in the BIM software in LOD4. This maximum level of detail, although not necessary for the management of 3D cadastral information, it was targeted and tested in the platform. Afterwards, the legal information was linked to property boundaries specified in the first step and visualized in 3D via the IFC standard. This standard after exported from BIM software, it was utilized as physical and legal model and imported into ArcGIS Pro. IFC classes were converted into feature classes in a File Geodatabase in order to be readable from ArcGIS Pro. The aforementioned data plus the 3D spaces of the block generated in the GIS software were shared in the ArcGIS Online. Ultimately, a platform was created using these shared layers and applying HTML and JavaScript programming languages.

\subsection{Case study}

\subsubsection{Study Area, Data and Software}

City block 464 in the area of Chalandri, Athens and a newly fourfloor building located at Kithaironos 21 street, in the same buildings' block were used for applying GIS and BIM technology accordingly.

The physical boundaries of the building derived from 2D architectural and survey plans, while the elevation, absolute and relative, was obtained from section plans (provided by the Municipality of Chalandri). Concerning the remained block's buildings, footprints from the OSM (Open Street Map) basemap were utilized in the GIS environment while the number of floors was accounted by Google Earth, having the same geometry. Furthermore, we assigned the value of " 3 meters" as typical height for each floor.

The legal data of the registered property of the city block is stored in 2D documents including an index map with coordinates of space boundaries referenced in EPSG:2100 system and cadastral tables and dossiers including verbal descriptions. The legal information were requested by the local cadastral office. Dealing with the condominium units in the four-floor building, we worked with architectural plans that included the geometrical boundaries and the attributes for the apartments of each floor.

\subsubsection{Analysis of methodological steps}

The following sections describe the methodology in detail for the development of the platform in five steps.

\section{Step 1: Creation of the 3D physical model in Revit Architecture}

Firstly, a CAD footprint of the building created by the coordinates of the survey plan and the 'survey point' from Revit software were used aiming at the georeference of the model. Survey point is a characteristic point in every Revit project which represents a known point in the physical world.
Afterwards, the 3D physical objects following the georeferenced CAD footprint and 2D architectural plans that were imported and georeferenced in the Revit environment depending on the floor for more accuracy, were created. 3D physical objects can be utilized as auxiliary components to facilitate understanding of such boundaries for non-specialists (Atazadeh et al., 2016). Building elements such as walls, floors, windows and slabs comprise the spaces that are useful for the representation of $3 \mathrm{D}$ legal objects. The geometry was defined using the $2 \mathrm{D}$ plans and sections as mentioned above, while semantic information (such as materials and other properties) enriched the 3D objects. The resulting model reaches the LOD4 (Figure 2).

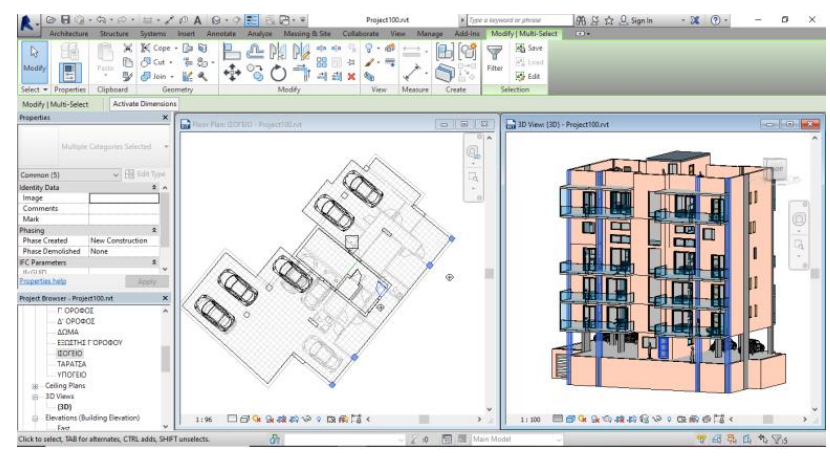

Figure 1. BIM model, LOD4

Source: Result of processing in Revit software

\section{Step 2: Generation of 3D legal model via IFC standard}

As mentioned in sub-section 3.2., IFC standard may be used as a viable data model for the 3D management and visualization of complex RRRs, as it comprises a set of spatial and semantic data. IFC model is the exchange format for exporting Revit modelling. Therefore, some additional processes had to be completed in Revit environment in order to insert the legal dimension in the model.

Firstly, 'Area' capability was utilized in Revit, which gives user the ability to identify $2 \mathrm{D}$ boundaries for each $3 \mathrm{D}$ legal object when needed. This tool can be applied to existing building elements like Wall entity, creating exterior, interior or median boundaries as well as 2D lines without more elements needed. In the next stage, legal information was inserted via 'Schedule' capability of Revit that operates as a table, having information for every chosen entity such as Area Schedule. Therefore, 2D spaces with Area tool, according to 2D drafts and Area Schedule embedded with the semantic data were created for every RRR. Every 2D space in Revit is matched with 3D IfcSpace entity in the exported IFC model that contains the legal information generated by the Schedule.

Apart from 3D, 2D land parcels pertained to each property were identified with 'Toposurface' tool. This tool gives the user the ability to define 2D boundaries on a surface based on DTM or specific height value. In order to simplify this process, a CAD file created by the cadastral index map was inserted and used the level of the ground of the case study building as common value. By the same token, 'Topography' Schedule was embedded with legal information related to 2D land parcels. So, 2D parcels in Revit are matched with 2D IfcSite entity in the exported IFC model.

In addition to spatial elements, IFC model contains the physical entities of the Revit one. There are many open IFC viewers like 
Solibri Model Viewer and BIM Vision Viewer that keep the geometry and semantic data, depending on the choices selected during the export process. This process is executed via the MVD (Model View Definition) standard, which is a set of information from the IFC model. The figure 2(a) represents the 3D legal objects from the IfcSpace entity while the 2(b) depicts the whole IFC model.

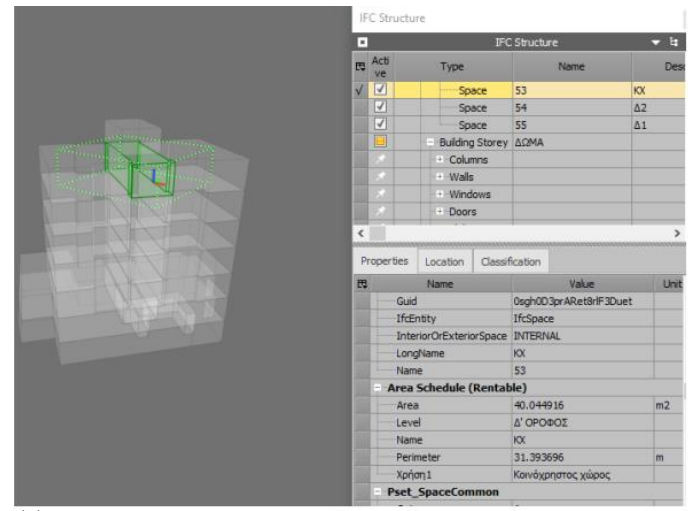

(a)

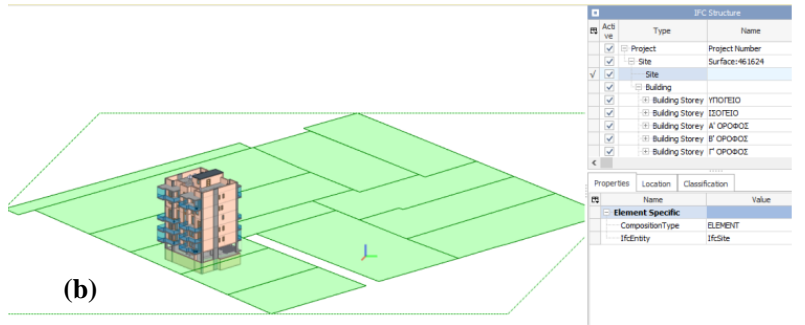

Figure 2. (a) 3D IfcSpace entity and (b) IFC model Source: View of IFC model in BIM Vision free software

As seen in more details in figure $2 b$, there is a common surface in the IfcSite entity in the exported IFC model, without having the proper information, while in Revit environment 2D land parcels were represented separated and each one with its own geometry and descriptive data. This is a limitation of IFC2X3 version to preserve information for a single surface created first. Trying the next version IFC4 the result was the same.

\section{Step 3: Integration of 3D physical and legal model with GIS}

One of the main reasons for selecting ArcGISPro v.2.2. as GIS software, was its capability to read direct Revit files. We created a local scene and defined EPSG:2100 as coordinate reference system so that the georeferenced BIM model would be in the correct position. Therefore, the BIM model with the physical elements of the building was inserted into the GIS environment, preserving its geometry and semantic data. As seen in figure 3, 2D land parcels that could not be managed as sub-surfaces in the IFC legal model, they are represented in the right way in the GIS environment.

Concerning to IFC model, ArcGISPro cannot yet read this standard. So, IFC had to be converted into a readable format with the two tools operated in the GIS software. The first tool namely 'Quick Import' exists in the 'Interoperability Tools' Toolbox that can convert formats to Geodatabase via FME Reader, while the second one 'Spatial ETL Tools' executed in the FME Workbench environment converts formats to more complex structures. Using these tools, it was detected that the 3D geometry of the IFC model was correct but the semantic information defined as 'Property sets' in the Schedules was lost. Part of the descriptive data existed by default in the tables like 'IfcGUID' that operates as the ID of IFC entities. Eventually, the 3D geometry of the 'IfcSpace' entity has been kept that represents the 3D legal objects in the GIS and joined the 'Area Schedule' as descriptive table using as key field the 'IfcGUID' column with the proper tools in the software.

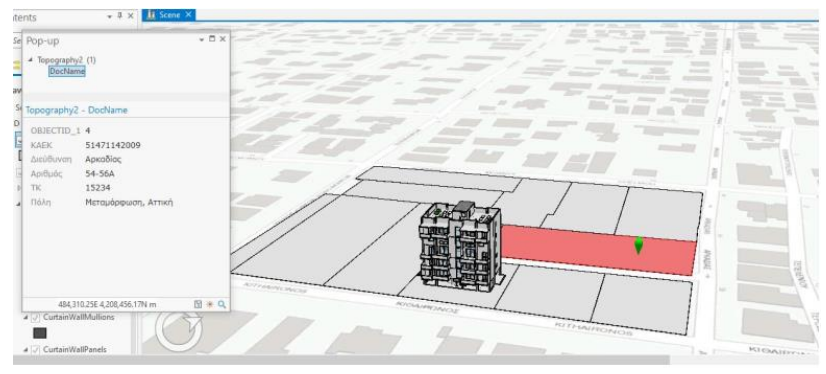

Figure 3. Revit model in LOD4

Source: Result of processing in ArcGIS Pro v.2.2.

\section{Step 4: 3D Modelling of the block in the GIS}

In this sub-section the process of the 3D modelling of the legal entities of the block is described, using tools from the GIS software. As referred in sub-section 4.2, OSM was selected as basemap for the footprints of the buildings, while Google Earth as tool in order to represent the block in 2D based on satellite imagery and $3 \mathrm{D}$ from various angles in order to calculate the number of floors for each structure.

As there is not available information about the legal objects of the block, we assumed that each building on a land parcel constitutes a vertical property ownership, while each floor a horizontal property. Therefore, the legal data about these entities were adjusted from those of the $2 \mathrm{D}$ land parcels. In addition, the horizontal properties per building had the same geometry defined from the footprints while the value of ' $3 \mathrm{~m}$ ' was selected as the typical height for each floor. Pertaining to the ground elevation, the level of the ground of the case study building was used as common value. As depicted in figure 4 , we created different layers for the legal objects of the case study building and the remained of the block using the red and green color accordingly.

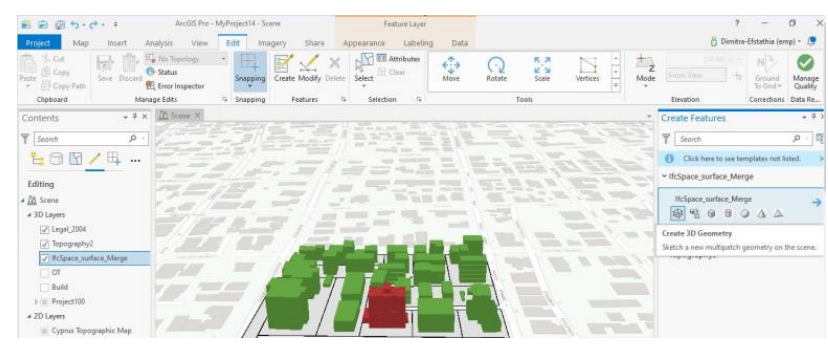

Figure 4. Integrated BIM - GIS model

Source: Result of processing in ArcGIS Pro v.2.2.

\section{Step 5: Development of an Integrated BIM-GIS Platform}

The last step describes the process for the development of the platform, to integrate data from BIM and GIS environment in order to manage and represent 3D land administration data. ArcGIS Online was selected as the online source that hosts the aforementioned data as 3D Scenes. Therefore, it was needed to convert the data from the integrated GIS environment to $3 \mathrm{D}$ Scenes via tools, namely 'Create Building Scene Layer Package' $\&$ 'Create 3D Object Scene Layer Package' for physical and legal 
objects accordingly. Moreover, each entity had its layer for better management. After the process of importing data in the proper format in the ArcGIS Online, a 3D Web Scene was created consisted of them, having the required coordinate system.

Subsequently, HTML and JavaScript programming languages were used for the structure of the platform and the visualization of data accordingly. In particular, ArcGIS API for JavaScript via CDN (Content Delivery Network, hosted version) gave us the capability to call widgets using ready codes that could be adjusted to our needs. In the website of ESRI there is wide variety of widgets for management and analysis of 2D and 3D web maps. Four of them were selected:

1. Intro to SceneLayer: This tool calls 3D Web Scenes from ArcGIS Online based on their ID and creates layers. The name of each layer can change in ArcGIS Online environment, while it can be activated or turned off in the user's interface.

2. Measurement in 3D: This tool gives users the capability to measure length and calculate area and perimeter.

3. BuildingSceneLayer with Slice widget: This widget gives users the capability to create vertical and horizontal slices in order to be visible the hidden entities in the building. During this process, users can exclude layers from slice.

4. Highlight the SceneLayer: This tool highlights spatial entities based on an attribute defined in the code, creating an interactive table. We selected the field 'KAEK' as attribute because it is the unique number for each land parcel. So, choosing the preferred 'KAEK' button, the 2D land parcel with this attribute is highlighted. Moreover, when users zoom in the map, the table changes and contains the values from the spatial objects that are visible in the screen.

Every widget was put in a frame defined with the tags from HTML programming language. Screenshots from the platform are depicted in the following figures.

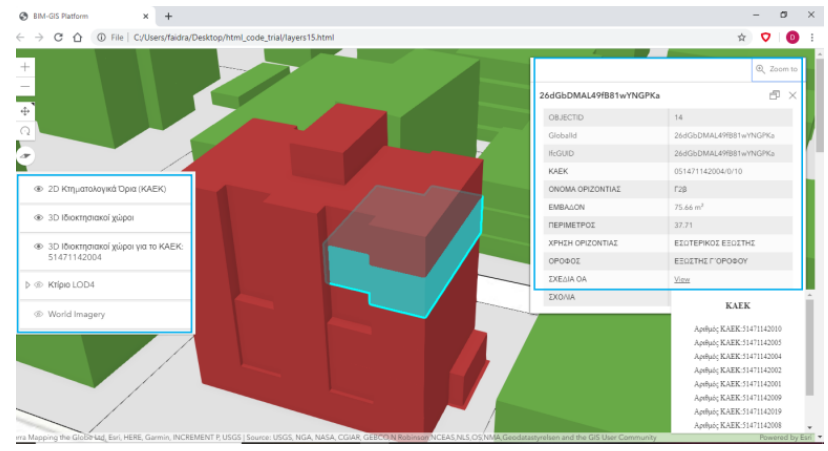

Figure 5. User's interface of BIM-GIS Platform after an entity being selected.

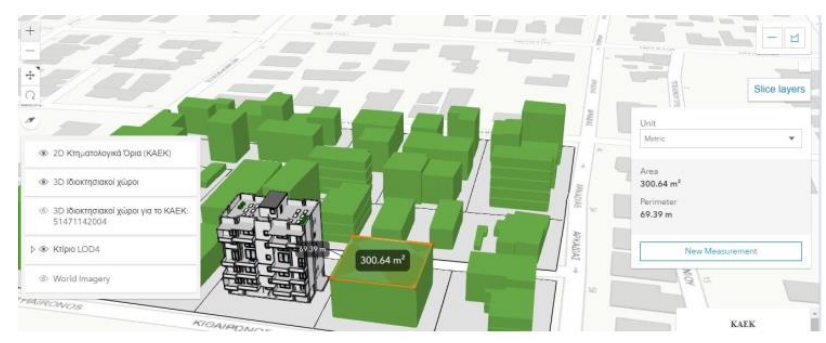

Figure 6. User's interface of BIM-GIS Platform after the measurement tool being executed.

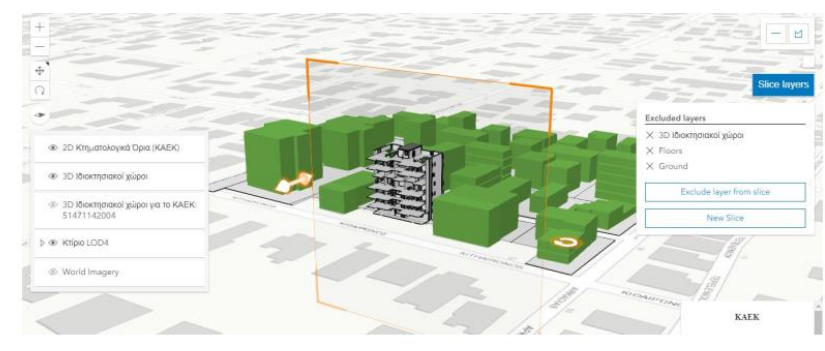

Figure 7. Results of using 'Slice tool' at the four-floor building.

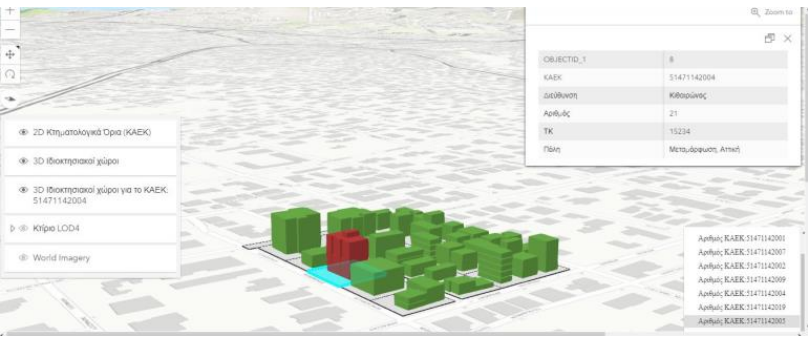

Figure 8. Results of using 'Highlight tool' at the entity of 2D parcels based on 'KAEK' attribute.

\section{CONCLUSION AND FUTURE WORK}

Over the last decade, research highlighted the need for a LAS as an integral part of 3D city models, using BIM and GIS systems that protect and ensure land properties, thus improving the quality of citizens' life. As a broader step beyond the existing literature research, the aim of this paper was to integrate GIS and BIM data, investigating new ways for the combined management of 3D cadastral and building information, in a generalized framework. Namely, Revit was used as BIM software, ArcGIS Pro as GIS one and the adequacy of IFC standard for the integration of 3D spatial information with the two systems in an interoperable way was tested. IFC was selected due to its capability to manage and visualize complex 3D RRRs and ArcGIS Pro like the previous researches owing to the last release of this system that provides a range of tools for bringing geographic context to BIM data.

In this context, a web-based platform was developed, consisted of physical and legal objects for the city block 464 in the area of Chalandri, Athens. Our research suggests that users from different organizations should share and exchange cadastral information during the whole life cycle of buildings, aiming at a comprehensive 3D LAS, representing complex RRRs. Despite the pilot character of this platform, the results illustrate that linking BIM, GIS and cadastral models after the construction phase, will enable a proper information exchange among different units via the interoperable character of IFC standard.

At one hand, the developed platform gives helpful basic functions that can assist in research, exploration, display, simulation and analysis based on e-collaboration. Specifically, users can select a suitable basemap and navigate through the block scene from different viewing directions, imagining the actual representation of the City. In addition, query and measurement tools provide users with the ability to execute queries about the facilities and 3D/2D RRRs and compute distances and areas for objects selected.

On the other hand, this application highlights limitations that need to be further researched. Even though IFC standard may be considered as a viable physical and legal model, when expected to manage $2 \mathrm{D}$ objects and be integrated with GIS, some problems 
appear. First limitation is about IFC versions to preserve information for only the surface that is created first, representing 2D legal objects inefficiently. The second problem appeared when IFC model was converted to other format in order to insert the 3D legal objects, IfcSpace entity, in GIS environment. While the 3D geometry was right, most of the semantic data was lost, apart from by default attributes. The first issue was addressed by inserting the Revit model in the GIS that kept the geometry and semantic data, while the second one by using the basic GIS tools for joining attributes in 3D shapes.

Further research must focus on the methods for sharing and integrating cadastral information on building and city scale, in order to solve the aforementioned issues. Another area of interest for future research could be the enrichment of the platform with data from other elements of the city in order to manage infrastructure and city facilities efficiently and effectively. To conclude, the development of algorithms to automatically run some processes would save time and enrich interoperability.

\section{ACKNOWLEDGEMENTS}

The authors would like to thank Ordnance Survey GB (https://www.ordnancesurvey.co.uk) and 1Spatial (https://1spatial.com/) for sponsoring the publication of this paper.

\section{REFERENCES}

Aien, A., Kalantari, M., Rajabifard, A., Williamson, I., Wallace, J., 2013. Towards integration of 3D legal and physical objects in cadastral data models. Land Use Policy, 35(0), pp.140-154. doi.org/10.1016/j.landusepol.2013.05.014.

Aien, A., Rajabifard, A., Kalantari, M., Shojaei, D., 2015. Integrating Legal and Physical Dimensions of Urban Environments. ISPRS Int. J. Geo-Inf.2015, 4, 1442-1479. doi: 10.3390/ijgi4031442.

Arunkumar, S., Suveetha, V., Ramesh, A., 2018, A feasibility study on the implementation of building information modeling (BIM): from the architects' \& engineers' perspective. Asian Journal of Civil Engineering, volume 19, pp. 239-247.

Atazadeh, B., Kalantari, M., Rajabifard, A., Ho, S., Ngo, T., D., 2016. Building Information Modelling for High-rise Land Administration. Transactions in GIS, 21(1):91-113. doi.org/10.1111/tgis.12199.

Atazadeh, B., Kalantari, M., Rajabifard, A., Champion, T., Ho, S., 2016. Harnessing BIM for 3D Digital Management of Stratified Ownership Rights in Buildings. In Proceedings of ' $F I G$ Working Week 2016 Recovery from Disaster', Christchurch, New Zealand 2-6 May, Australia.

Atazadeh B., Rajabifard, A., Zhang, Y., Barzegar, M., 2019. Querying 3D Cadastral Information from BIM Models. ISPRS Int. J. Geo-Inf. 2019, 8, 329. doi:10.3390/ijgi8080329.

Biljecki, F., Stoter, J., Ledoux, H., Zlatanova, S., Çöltekin, A. 2015. Applications of 3D City Models: State of the Art Review. ISPRS International Journal of Geo-Information, 4 (4):28422889. doi:10.3390/ijgi4042842.
Borrmann, A., Konig, M., Koch, C., Beetz, J., 2018, Building Information Modeling. Springer International Publishing, pp.584, doi: 10.1007/978-3-319-92862-3.

Clarke, K. C., 1986. Advances in geographic information systems, computers, environment and urban systems, Vol. 10, pp. 175-184.

Dimopoulou, E., Elia, E., 2012, Legal Aspects of 3D Property Rights, Restrictions and Responsibilities in Greece and Cyprus. 3rd International Workshop on 3D Cadastres: Developments and Practices, 25-26 October 2012, Shenzhen, China.

El-Hallaq, M., A., Alastal, A., Salha, R., A., 2019. Enhancing Sustainable Development through Web Based 3D Smart City Model Using GIS and BIM. Case Study: Sheikh Hamad City. Journal of Geographic Information System, 11(03), 321-330. doi: 10.4236/jgis.2019.113019.

Enemark, S., 2009. Land Administration Systems. Map World Forum, Hyedrabad, India.

Janecka, K., 2019. Standardization supporting future smart citiesa case of BIM/GIS and 3D Cadastre. GeoScape, 13(2):106-113. doi: 10.2478/geosc-2019-0010.

Hedges, K., American Institute of Architects, 2017, Architectural Graphic Standards, pp.688.

Kalogianni, E., Van Oosterom, P., Dimopoulou, E., Lemmen, C., 2020. 3D Land Administration: A Review and a Future Vision in the Context of the Spatial Development Lifecycle. ISPRS Int. J. Geo-Inf. 2020, 9, 107. doi:10.3390/ijgi9020107.

Kanickaraj, L., Geographic Information Systems (GIS) Defined, 2018, ARC Advisory Group.

Kumar, K., Labetski, A., Ohori, K., A., Ledoux, H., Stoter, J., 2019. The LandInfra standard and its role in solving the BIM-GIS quagmire. Open Geospatial Data, Software and Standards (2019), 4:5. Doi:10.1186/s40965-019-0065-z.

Maliene, V., Grigonis, V., Palevičius, V., Griffiths, S., 2011. Geographic information system: Old principles with new capabilities. Urban Design International. 16 (1): 1-6. doi:10.1057/udi.2010.25.

Meulmeester, R., W., E., 2019. BIM Legal. Proposal for Defining Legal Spaces for Apartment Rights in the Dutch Cadastre Using the IFC Data Model. Master's Thesis, Delft University of Technology.

Oldfield, J.,Van Oosterom P., Beetz, J., Krijnen, T., 2017, Working with Open BIM Standards to Source Legal Spaces for a 3D Cadastre. ISPRS Int. J. Geo-Inf. 2017, 6(11), 351, https://doi.org/10.3390/ijgi6110351.

Rajabifard, A., 2014, 3D Cadastres and Beyond. 4th International Workshop on 3D Cadastres, 9-11 November 2014, Dubai, United Arab Emirates. 
Sun, J., 2019. The integration of 3D Geodata and BIM Data in 3D City Models and 3D Cadastre. Licentiate Thesis. Stockholm, Sweden.

Sun, J., Mi, S., Olsson, P., Paulsson, J., Harrie, L., 2019. Utilizing BIM and GIS for Representation and Visualization of 3D Cadastre. ISPRS Int. J. Geo-Inf. 2019, 8(11), 503. doi:10.3390/ijgi8110503.

Van Oosterom, P., 2018. Best Practices 3D Cadastre-Extended Version. International Federation of Surveyors (FIG), Copenhagen, Denmark, ISBN 978-87-92853-64-6, ISSN 23118423.

Wang, H., Pan, Y., Luo, X., 2019, Integration of BIM and GIS in sustainable built environment: A review and bibliometric analysis. Automation in Construction, Volume 103, pp. 41-52, https://doi.org/10.1016/j.autcon.2019.03.005.

Zhixuan, Y., Tuladhar, A., Rajabifard, A., 2015. 3D City Governance: Towards an Integrated Sustainability. FIG-ISPRS workshop: International Workshop on Role of Land Professionals and SDI in Disaster Risk Reduction: In the Context of Post 2015 Nepal Earthquake. Kathmandu, Nepal. 